\title{
A Scientific Validation of Antihyperglycemic and Antihyperlipidemic Attributes of Trichosanthes dioica
}

\author{
Prashant Kumar Rai, ${ }^{1,2}$ Sharad Kumar Gupta, ${ }^{1}$ Amrita Kumari Srivastava, ${ }^{1}$ \\ Rajesh Kumar Gupta, ${ }^{3}$ and Geeta Watal ${ }^{1}$ \\ ${ }^{1}$ Alternative Therapeutics Unit, Drug Development Division, Medicinal Research Laboratory, Department of Chemistry, \\ University of Allahabad, Allahabad 211 002, India \\ ${ }^{2}$ Department of NMR, All India Institute of Medical Sciences, New Delhi 110 029, India \\ ${ }^{3}$ School of Vocational Studies and Applied Chemistry, Gautam Buddha University, Greater Noida, Uttar Pradesh 201310, India
}

Correspondence should be addressed to Geeta Watal; geetawatal@gmail.com

Received 6 June 2013; Accepted 27 June 2013

Academic Editors: D. K. Miller, F. J. Miranda, and R. Villalobos-Molina

\begin{abstract}
Copyright (C) 2013 Prashant Kumar Rai et al. This is an open access article distributed under the Creative Commons Attribution License, which permits unrestricted use, distribution, and reproduction in any medium, provided the original work is properly cited.

The present study was undertaken to scientifically validate the antidiabetic activity of aqueous fruit extract of Trichosanthes dioica Roxb. (Family: Cucurbitaceae) which has been traditionally used for managing diabetes mellitus. This plant commonly known as "Sespadula" in English has not been explored scientifically so far for its glycemic potential except by our research group. The study was conducted with variable doses on normal, mild, and severe diabetics models, and several biochemical parameters including blood glucose level (BGL) were assessed. Maximum fall in BGL of $23.8 \%$ in normal rats and of $31.3 \%$ in mild diabetic rats was observed during their fasting blood glucose (FBG) and glucose tolerance test (GTT) with the dose of $1000 \mathrm{mg} \mathrm{kg}^{-1}$. In severely diabetic animals after 4 weeks treatment with FBG, postprandial glucose, total cholesterol, and triglyceride levels were reduced by 28.7, 30.7, 57.2, and 18.5\%, whereas high density lipoprotein, total protein, hemoglobin, and body weight were increased by 33.0 , 36.7, 15.7 and $16.7 \%$, respectively. Moreover, urine sugar was reduced from +4 to +1 . Thus, the study scientifically validates the traditional use of $T$. diocia in diabetes management and could be developed as an effective oral agent for treating diabetes mellitus and complications associated with it.
\end{abstract}

\section{Introduction}

Diabetes mellitus and its complications are becoming a global burden and have to be dealt with firmly. Hypercholesterolemia associated with this dreaded disease $[1,2]$ has been ranked as one of the greatest risk factors contributing to the prevalence and severity of coronary heart diseases [3]. World Health Organization (WHO) has recommended the development of oral hypoglycemic agents from medicinal plants [4] as herbal natural remedies to treat diabetes mellitus being cost-effective and safe [5]. Many plants have been explored scientifically and systematically and proved to be beneficial for the treatment of diabetes mellitus by our research group [6-10]. The present study is a further effort in the direction of developing a novel, oral antidiabetic agent coupled with antilipidemic efficacy of high potential with minimal or no side effects.

Trichosanthes dioica (T. dioica) Roxb. (Family: Cucurbitaceae) is commonly known as "Sespadula" in English and "Parwal" in Hindi and is widely grown throughout India [11]. Its fruits are used as vegetable from the time immemorial and have also been proved as hypocholesterolemic and hypoglyceridimic in case of normal animals after shade drying and mixing in the food [12]. Recently its seeds and leaves have also been experimentally proven as antidiabetic agents by our research group $[13,14]$. Phytochemical investigation of its fruits and seeds reveal the presence of all those classes of compounds which are responsible either for managing diabetes or its complications, namely, flavonoids $[15,16]$, alkaloids [17-22], glycosides [23, 24], terpenes, and sterols 
[25-27]. This plant also serves as a rich source of minerals such as $\mathrm{Mg}, \mathrm{Na}, \mathrm{K}, \mathrm{Cu}$, and $\mathrm{S}$ [28] whose significant role in controlling and managing diabetes is well known and cannot be ignored as specific concentration of these minerals have been reported to take part in carbohydrate metabolism as well as insulin release [29-32]. The present study was designed to scientifically validate the use of $T$. dioica in folklore medicines for treating diabetes by evaluating its glycemic potential. The effect was observed on blood glucose level (BGL) of normal and streptozotocin- (STZ-) induced mild and severely diabetic rats with graded doses. Biochemical parameters such as fasting blood glucose (FBG) in addition to lipid profile and other parameters were considered. Results of all valuable scientific measures taken into consideration reveal that along with antidiabetic and antilipidemic activities it has high nutritive value also as the plant has been well known since ages for regaining health post sickness [33].

\section{Materials and Methods}

2.1. Plant Material. Fresh unripe fruits $(6 \mathrm{~kg})$ of T. dioica were purchased from the local market of Allahabad, U P (India) and authenticated by Professor Satya Narayan, Taxonomist, Department of Botany, University of Allahabad, Allahabad, U P, India. A voucher specimen (AA512) has been submitted to the University herbarium. The fruits were cut into small pieces and shade dried. The dried pieces were mechanically crushed and extracted with distilled water using soxhlet at temperature $\left(80-100^{\circ} \mathrm{C}\right)$ up to $36 \mathrm{~h}$. The extract was filtered and concentrated in rotatory evaporator at $35 \pm 5^{\circ} \mathrm{C}$ under reduced pressure, to obtain semisolid material, which was then lyophilized to get a powder (yield: $14.9 \% \mathrm{w} / \mathrm{w}$ ).

2.2. Experimental Animals. Experiments were performed in 6-8-week-old, healthy, male albino Wistar rats, of body weight $150-200 \mathrm{~g}$. Animals obtained from National Institute of Communicable Diseases (NICD) New Delhi, India were housed under standard environmental conditions $\left(25 \pm 2^{\circ} \mathrm{C}\right.$ temperature, $50 \pm 5 \%$ humidity with a $12 \mathrm{~h}$ each of dark and light cycle) and maintained with free access to water and a standard laboratory diet (carbohydrates; $30 \%$, proteins; $22 \%$, lipids; $12 \%$, and vitamins; $3 \%$ ) ad libitum. The study was approved by the Institutional Ethical Committee.

2.3. Induction of Diabetes. Diabetes was induced by a single intraperetonial injection of freshly prepared Streptozotocin (STZ) (purchased from Sigma Aldrich Chem. Co., St. Louis, USA) at a standard dose of $55 \mathrm{mg} \mathrm{kg}^{-1}$ bw [34] in $0.1 \mathrm{M}$ citrate buffer ( $\mathrm{pH}$ 4.5) to a group of overnight fasted rats. After 3 days of STZ administration, depending on their glucose levels, the animals were divided into two groups, mild and severely diabetic animals as follows:

(i) Mild diabetic (MD): FBG $150-250 \mathrm{mg} \mathrm{dL}^{-1}$

(ii) Severely diabetic (SD): $F B G>250 \mathrm{mg} \mathrm{dL}^{-1}$.

2.4. Estimation. Blood samples were collected from the tail vein from the afore mentioned overnight fasted rats, and the BGL were estimated by glucose oxidase method [35] using standard kit of Bayer Diagnostics India Limited, New Delhi, India. TC, TG, and HDL levels in serum were measured spectrophotometrically by the method prescribed by manufacturer $[36,37]$ using standard kit from Bayer Diagnostics India Limited, New Delhi, India. However, very low density lipoprotein (VLDL) and low density lipoprotein (LDL) cholesterol were calculated by Friedwald's formula, $[\mathrm{VLDL}=\mathrm{TG} / 5$ and $\mathrm{LDL}=\mathrm{TC}-(\mathrm{VLDL}+\mathrm{HDL})][38]$. Total protein (TP) [39] and hemoglobin ( $\mathrm{Hb})$ [40] were also estimated in blood before and after the treatment of four weeks duration. Urine sugar (US) was detected by reagent based Uristix from Bayer Diagnostics India Limited, New Delhi, India. All the parameters inclusive of bw were measured initially before the treatment and then monitored regularly every week up to 4 weeks treatment.

2.5. Experimental Design. Initial screening of the aqueous extract for the hypoglycemic activity was done with a range of variable doses in overnight fasted normal healthy rats by conducting FBG and glucose tolerance test (GTT) studies. The antidiabetic effect was assessed in mild-diabetic models fasted overnight with the same range of doses by studying their effect on FBG and GTT levels. The results were compared with a reference drug, Tolbutamide, for positive control. Severely diabetic animals were used for evaluating the antidiabetic and hypolipidemic potential of the most effective dose identified in case of normal and mild-diabetic animals. Effect of this dose was also studied on TC, TG, HDL, $\mathrm{TP}, \mathrm{Hb}, \mathrm{US}$, and bw of severely diabetic rats.

2.6. Assessment of Hypoglycemic Activity in Normal Healthy Rats. Five groups of six rats each were used in the experiment. Group I served as untreated control received vehicle (distilled water only), and animals of groups II, III, IV, and V received aqueous fruit extract suspended in distilled water at doses 500, 750, 1000, and $1250 \mathrm{mg} \mathrm{kg}^{-1}$ bw, respectively. Blood samples were collected from tail vein at $1.5,3,4.5$, and $6 \mathrm{~h}$ after administering the extract.

2.7. Assessment of Antidiabetic Activity by GTT in MildDiabetic Rats. The antidiabetic effect of aqueous extract of T. dioica fruits in mild-diabetic rats was also assessed for improvement in glucose tolerance. The rats were divided into six groups. Group I served as control, received vehicle (distilled water only), whereas variable doses of 500, 750, 1000 , and $1250 \mathrm{mg} \mathrm{kg}^{-1}$ bw of fruit extract was given orally to groups II, III IV, and V, respectively. BGLs were checked first after 90 minutes of treatment considered as " 0 " $\mathrm{h}$ value and then $2 \mathrm{~g} \mathrm{~kg}^{-1}$ bw glucose was given orally to all the groups. BGLs were further checked up to three hours at regular intervals of $1 \mathrm{~h}$ each, considered as 1,2 , and $3 \mathrm{~h}$ values. The results were compared with group VI of rats, which were treated with $250 \mathrm{mg} \mathrm{kg}^{-1}$ bw of Tolbutamide (hypoglycemic agent) as a reference drug for positive control. 
TABLE 1: Effect of graded dose of Trichosanthes dioica fruit aqueous extract on FBG of normoglycemic rats (mean \pm S.D.).

\begin{tabular}{|c|c|c|c|c|c|c|}
\hline \multirow{3}{*}{ Experimental Groups } & \multirow{3}{*}{ Treatment $\left(\mathrm{mg} \mathrm{kg}^{-1} \mathrm{bw}\right)$} & \multicolumn{5}{|c|}{ Blood glucose levels $\left(\mathrm{mg} \mathrm{dL}^{-1}\right)$} \\
\hline & & \multirow{2}{*}{$\begin{array}{c}\text { Pretreatment } \\
\text { FBG }\end{array}$} & \multicolumn{4}{|c|}{ Post treatment (hours) } \\
\hline & & & 1.5 & 3.0 & 4.5 & 6.0 \\
\hline Control (I) & Distilled water & $69.5 \pm 3.9$ & $69.3 \pm 3.2$ & $70.0 \pm 4.6$ & $70.1 \pm 3.8$ & $69.2 \pm 4.2$ \\
\hline Extract (II) & 500 & $70.0 \pm 3.2$ & $68.8 \pm 4.4$ & $66.1 \pm 4.6$ & $62.4 \pm 5.1^{*}$ & $60.1 \pm 3.8$ \\
\hline Extract (III) & 750 & $68.2 \pm 3.2$ & $65.9 \pm 4.4$ & $62.1 \pm 4.6$ & $58.7 \pm 5.1^{*}$ & $55.6 \pm 3.8$ \\
\hline Extract (IV) & 1000 & $71.4 \pm 3.2$ & $68.1 \pm 4.4$ & $63.5 \pm 4.6$ & $58.9 \pm 5.1^{* *}$ & $54.3 \pm 3.8^{*}$ \\
\hline Extract (V) & 1250 & $72.1 \pm 4.6$ & $70.4 \pm 4.2$ & $67.1 \pm 4.8$ & $65.8 \pm 3.7^{* *}$ & $60.4 \pm 4.5^{*}$ \\
\hline
\end{tabular}

${ }^{*} P<0.05,{ }^{* *} P<0.01$ compared with control.

TABLE 2: Effect of graded doses of T. dioica fruits aqueous extract on BGL during GTT in mild-diabetic rats each value shown in Mean \pm S.D. $(n=6)$.

\begin{tabular}{|c|c|c|c|c|c|c|}
\hline \multirow{3}{*}{ Experimental Groups } & \multirow{3}{*}{ Treatment $\left(\mathrm{mg} \mathrm{kg}^{-1} \mathrm{bw}\right)$} & \multicolumn{5}{|c|}{ Blood glucose levels $\left(\mathrm{mg} \mathrm{dL}^{-1}\right)$} \\
\hline & & \multirow{2}{*}{$\begin{array}{c}\text { Pretreatment } \\
\text { FBG }\end{array}$} & \multicolumn{4}{|c|}{ Post treatment (hours) } \\
\hline & & & 0 & 1 & 2 & 3 \\
\hline Control (I) & Distilled water & $175.4 \pm 2.6$ & $173.8 \pm 3.2$ & $391.2 \pm 4.1$ & $317.4 \pm 3.4$ & $280.5 \pm 4.2$ \\
\hline Extract (II) & 500 & $174.8 \pm 4.6$ & $169.2 \pm 4.4$ & $329.3 \pm 2.9$ & $270.4 \pm 3.5$ & $234.3 \pm 2.9$ \\
\hline Extract (III) & 750 & $168.4 \pm 3.5$ & $165.4 \pm 3.5$ & $314.5 \pm 3.1$ & $252.6 \pm 4.1$ & $197 \pm 3.7$ \\
\hline Extract (IV) & 1000 & $166.6 \pm 2.9$ & $151.3 \pm 4.6$ & $258.5 \pm 3.3$ & $217.4 \pm 4.4^{*}$ & $192.4 \pm 3.2^{* *}$ \\
\hline Extract (V) & 1250 & $170.3 \pm 3.9$ & $163.4 \pm 3.8$ & $309.6 \pm 4.6$ & $250.7 \pm 3.9^{*}$ & $200.1 \pm 4.2^{*}$ \\
\hline Tolbutamide (VI) & 250 & $171.2 \pm 4.8$ & $159.3 \pm 3.6$ & $259.5 \pm 4.1$ & $212.4 \pm 3.2$ & $192.1 \pm 3.4^{* *}$ \\
\hline
\end{tabular}

${ }^{*} P<0.05,{ }^{* *} P<0.01$ compared to the control at the corresponding time.

2.8. Assessment of Antidiabetic Activity in Severely Diabetic Rats. Three groups of 6 rats each were used in the experiment. Groups I and II served as normal and severely diabetic control, whereas group III was treated once daily for 4 weeks with the dose of $1000 \mathrm{mg} \mathrm{kg}^{-1}$ bw identified as the most effective dose in case of normal and mild-diabetic rats. Various biochemical parameters such as FBG, PPG, TC, TG, HDL, LDL, VLDL, TP, Hb, US, and bw were taken into consideration and were estimated initially and then weekly up to 4 weeks.

2.9. $L D_{50}$ Experiment. Toxic effect of the aqueous extract was also studied by $\mathrm{LD}_{50}$ experiment. Two groups of rats of both the sexes ( 6 animals per group, 3 females and 3 males), weighing about 180-200 g were orally administered ten and fifteen times the most effective dose of $1000 \mathrm{mg} \mathrm{kg}^{-1}$ bw by a single dose of $10.0 \mathrm{~g}$ and $15.0 \mathrm{~g}$. of the aqueous extract of $T$. dioica fruits. Thereafter, rats were observed for gross behavioral, neurologic, autonomic, and toxic effects continuously for $24 \mathrm{~h}$. Food consumption, faeces, and urine were also examined at $2 \mathrm{~h}$ and then at $6 \mathrm{~h}$ intervals for $24 \mathrm{~h}$.

2.10. Statistical Analysis. Data were statistically evaluated using one-way ANOVA (Analysis of Variance), followed by a post hoc Newman-Keuls Multiple Comparison Test. The values were expressed as mean \pm S.D. and considered significant at $P<0.05$.

\section{Results}

3.1. Effect on FBG of Normal Healthy Rats. Table 1 describes the hypoglycemic effect of a single oral administration of variable doses of $500,750,1000$, and $1250 \mathrm{mg} \mathrm{kg}^{-1} \mathrm{bw}$ of aqueous fruit extract in normal healthy rats. Treated rats showed a regular fall of $14.0,18.2$, and $23.8 \%(P<0.01)$ from the doses of 500, 750, and $1000 \mathrm{mg} \mathrm{kg}^{-1} \mathrm{bw}$, respectively, after $6 \mathrm{~h}$. However, a fall of only $16.2 \%(P<0.01)$ was observed with the dose of $1250 \mathrm{mg} \mathrm{kg}^{-1}$ after the same interval of time.

3.2. Effect on GTT of Mild-Diabetic Rats. Table 2 illustrates the antidiabetic effect of single dose treatment of different doses of extract as mentioned previously and also of a dose of $250 \mathrm{mg} \mathrm{kg}^{-1}$ bw Tolbutamide (standard reference drug). The fall of $16.4,29.7,31.3$, and $28.6 \%(P<0.01)$ in BGL of mild-diabetic animals was observed after $3 \mathrm{~h}$ of glucose administration with the doses of 500, 750, 1000, and $1250 \mathrm{mg} \mathrm{kg}^{-1} \mathrm{bw}$, respectively. However, the dose of $250 \mathrm{mg} \mathrm{kg}^{-1}$ bw of Tolbutamide reduced BGL by $31.5 \%(P<$ $0.01)$ at $3 \mathrm{~h}$ during GTT in mild-diabetic rats, which is almost at par with the most effective dose of $1000 \mathrm{mg} \mathrm{kg}^{-1} \mathrm{bw}$ of the aqueous extract.

3.3. Effect on FBG, PPG, and Lipid Profile of Severely Diabetic Rats. Tables 3 and 4 describe the antidiabetic and antilipidemic effect of long-term treatment of 4 weeks with the dose of $1000 \mathrm{mg} \mathrm{kg}^{-1}$ bw of the extract on BGL and lipid profile of severely diabetic rats. Rats were treated with the most 
TABLE 3: Effect of most effective dose of Trichosanthes dioica fruit aqueous extract on BGL of severely diabetic rats (mean \pm S.D.).

\begin{tabular}{|c|c|c|c|c|c|c|}
\hline \multirow{2}{*}{ Experimental animals } & \multirow{2}{*}{ Treatment (aqueous extract) } & \multirow{2}{*}{ Pretreatment levels } & \multicolumn{4}{|c|}{ Posttreatment levels } \\
\hline & & & 7 days & 14 days & 21 days & 28 days \\
\hline \multicolumn{7}{|c|}{$\mathrm{FBG}\left(\mathrm{mg} \mathrm{dL}^{-1}\right)$} \\
\hline Normal (control I) & D W & $82.2 \pm 3.5$ & $85.6 \pm 2.8$ & $84.6 \pm 4.6$ & $83.9 \pm 4.8$ & $85.2 \pm 3.9$ \\
\hline SD (control II) & D W & $287.7 \pm 5.7$ & $290.9 \pm 3.4$ & $302.4 \pm 4.6$ & $299.9 \pm 4.9$ & $298.7 \pm 4.9$ \\
\hline SD (treated III) & $1000 \mathrm{mg} \mathrm{kg}^{-1}$ & $298.2 \pm 7.5$ & $274.3 \pm 4.6^{*}$ & $256.5 \pm 4.5^{* *}$ & $224.41 \pm 4.9$ & $212.3 \pm 5.2$ \\
\hline \multicolumn{7}{|c|}{ PPG $\left(\mathrm{mg} \mathrm{dL}^{-1}\right)$} \\
\hline Normal (control I) & D W & $160.8 \pm 5.2$ & $162.8 \pm 4.7$ & $163.2 \pm 4.9$ & $162.1 \pm 5.1$ & $161.8 \pm 4.1$ \\
\hline SD (control II) & D W & $447.7 \pm 4.8$ & $456.1 \pm 5.1$ & $458.9 \pm 3.6$ & $452.4 \pm 4.5$ & $462.8 \pm 3.8$ \\
\hline SD (treated III) & $1000 \mathrm{mg} \mathrm{kg}^{-1}$ & $438.2 \pm 3.5$ & $386.3 \pm 5.2^{* *}$ & $354.6 \pm 4.1^{*}$ & $322.2 \pm 4.3^{*}$ & $303.3 \pm 4.5^{* *}$ \\
\hline
\end{tabular}

${ }^{* *} P<0.01,{ }^{*} P<0.05$ compared to pretreatment levels.

TABLE 4: Effect of most effective dose of Trichosanthes dioica fruit aqueous extract on lipid profile of severely diabetic rats (mean \pm S.D.).

\begin{tabular}{|c|c|c|c|c|c|c|}
\hline \multirow{2}{*}{ Experimental animals } & \multirow{2}{*}{ Treatment (aqueous extract) } & \multirow{2}{*}{ Pretreatment levels } & \multicolumn{4}{|c|}{ Posttreatment levels } \\
\hline & & & 7 days & 14 days & 21 days & 28 days \\
\hline \multicolumn{7}{|c|}{ Total cholesterol $\left(\mathrm{mg} \mathrm{dL}^{-1}\right)$} \\
\hline Normal (control I) & $\mathrm{D} W$ & $95.8 \pm 6.4$ & $97.2 \pm 6.8$ & $98.7 \pm 5.9$ & $98.8 \pm 7.4$ & $97.5 \pm 6.8$ \\
\hline SD (control II) & D W & $118.6 \pm 4.4$ & $116.4 \pm 5.6$ & $114.9 \pm 5.2$ & $113.5 \pm 4.6$ & $115.3 \pm 5.5$ \\
\hline SD (treated III) & $1000 \mathrm{mg} \mathrm{kg}^{-1}$ & $116.4 \pm 5.8$ & $101.2 \pm 4.6^{* *}$ & $99.7 \pm 7.5^{*}$ & $93.6 \pm 5.2^{*}$ & $94.7 \pm 5.2^{* * *}$ \\
\hline \multicolumn{7}{|c|}{ HDL cholesterol $\left(\mathrm{mg} \mathrm{dL}^{-1}\right)$} \\
\hline Normal (control I) & $\mathrm{DW}$ & $28.5 \pm 4.2$ & $29.8 \pm 6.5$ & $30.5 \pm 4.6$ & $29.9 \pm 5.9$ & $28.7 \pm 6.6$ \\
\hline SD (control II) & D W & $24.8 \pm 2.8$ & $24.5 \pm 3.2$ & $22.6 \pm 8.6$ & $22.1 \pm 6.9$ & $22.5 \pm 7.6$ \\
\hline SD (treated III) & $1000 \mathrm{mg} \mathrm{kg}^{-1}$ & $21.0 \pm 3.5$ & $25.2 \pm 4.9^{*}$ & $25.3 \pm 5.1^{*}$ & $27.9 \pm 5.6^{* * *}$ & $28.0 \pm 6.8^{* *}$ \\
\hline \multicolumn{7}{|c|}{ Triglycerides $\left(\mathrm{mg} \mathrm{dL}^{-1}\right)$} \\
\hline Normal (control I) & $\mathrm{D} W$ & $90.9 \pm 4.8$ & $91.1 \pm 5.2$ & $91.9 \pm 5.4$ & $92.1 \pm 8.6$ & $92.6 \pm 8.6$ \\
\hline SD (control II) & $\mathrm{D} \mathrm{W}$ & $199.2 \pm 5.2$ & $197.8 \pm 4.8$ & $180.1 \pm 5.7$ & $191.3 \pm 5.9$ & $199.6 \pm 6.2$ \\
\hline SD (treated III) & $1000 \mathrm{mg} / \mathrm{kg}$ & $203.8 \pm 3.2$ & $161.4 \pm 4.4^{*}$ & $101.8 \pm 6.1^{* * *}$ & $89.3 \pm 5.7^{*}$ & $87.1 \pm 5.7^{*}$ \\
\hline
\end{tabular}

${ }^{* * *} P<0.001,{ }^{* *} P<0.01,{ }^{*} P<0.05$ as compared to pretreatment levels.

LDL and VLDL cholesterol ( $\left.\mathrm{mg} \mathrm{dL}^{-1}\right)$ were calculated with Friedwald's formula.

effective dose of $1000 \mathrm{mg} \mathrm{kg}^{-1}$ bw of the aqueous extract once a day at noon for four weeks. At the end of the treatment, the animals were compared with their own initial values and showed a significant reduction of $28.7 \%(P<0.001)$ in FBG and $30.7 \%(P<0.001)$ in PPG levels. The enhanced levels of TC and TG prior to the treatment, were brought down significantly to 57.2 and $18.5 \%,(P<0.01)$, respectively, after the treatment period. There was also significant improvement of 33.0\% $(P<0.05)$ observed in HDL level of severely diabetic treated group. The values calculated for LDL and VLDL from the previous data using Friedwald's formula also showed a marked reduction of 9.6 and $57.2 \%(P<0.05)$, respectively, in their levels.

3.4. Effect on TP and Hb US and BW of Severely Diabetic Rats. Tables 5 and 6 demonstrate the effect of afore mentioned long-term treatment of the aqueous extract on TP, Hb, US, and bw. The unique observation was a potential improvement of 36.7 and $15.7 \%(P<0.05)$ in TP and Hb levels of severely diabetic rats, respectively. In addition, 75\% $(P<0.05)$ decrease in urine sugar levels and $16.7 \%(P<0.05)$ increase in body weight was observed. Contrarily, enhanced levels of urine sugar accompanied with weight loss were observed in severely diabetic control group.

3.5. $L D_{50}$ Experiment. Experiment was carried out on normal healthy rats. The behavior of the treated rats appeared normal. No toxic effect was reported at doses up to 10 and 15 times of the identified most effective dose of the aqueous extract as no mortality was observed in any of these groups.

\section{Discussion}

Fruits of $T$. dioica have been used as a revitalizing agent since ages in the Indian food system as well as in Ayurvedic system of medicine [33]. Since its glycemic and lipidemic profiles have never been validated scientifically so far therefore the present study was undertaken in normal, mild, and severely diabetic models with variable doses. Moreover, the dose of $1000 \mathrm{mg} \mathrm{kg}^{-1}$ bw produced maximum fall in BGL of $23.8 \%$ within $6 \mathrm{~h}$ during FBG studies, whereas the GTT studies of mild-diabetic animals showed marked improvement of $31.3 \%$ in glucose tolerance within $3 \mathrm{~h}$ suggesting thereby that the active ingredients of the aqueous extract or their metabolites 
TABLE 5: Effect of most effective dose of Trichosanthes dioica fruit aqueous extract on TP and Hb of severely diabetic rats (mean \pm S.D.).

\begin{tabular}{|c|c|c|c|c|c|c|}
\hline \multirow{2}{*}{ Experimental animals } & \multirow{2}{*}{ Treatment (aqueous extract) } & \multirow{2}{*}{ Pre-treatment levels } & \multicolumn{4}{|c|}{ Post-treatment levels } \\
\hline & & & 7 days & 14 days & 21 days & 28 days \\
\hline \multicolumn{7}{|c|}{ Total protein $\left(\mathrm{mg} \mathrm{dL}^{-1}\right)$} \\
\hline Normal (control I) & $\mathrm{D} \mathrm{W}$ & $8.9 \pm 1.8$ & $8.7 \pm 1.2$ & $8.5 \pm 1.4$ & $8.8 \pm 2.1$ & $8.9 \pm 2.2$ \\
\hline SD (control II) & D W & $5.6 \pm 2.6$ & $5.1 \pm 2.5$ & $5.3 \pm 1.7$ & $5.7 \pm 2.3$ & $5.6 \pm 1.5$ \\
\hline SD (treated III) & $1000 \mathrm{mg} \mathrm{kg}^{-1}$ & $5.4 \pm 2.2$ & $5.6 \pm 2.4^{*}$ & $6.4 \pm 2.2^{*}$ & $7.1 \pm 1.9^{*}$ & $7.4 \pm 2.1^{*}$ \\
\hline \multicolumn{7}{|c|}{ Total hemoglobin $\left(\mathrm{g} \mathrm{dL}^{-1}\right)$} \\
\hline Normal (control I) & $\mathrm{D} W$ & $13.8 \pm 2.5$ & $13.8 \pm 2.5$ & $14.2 \pm 2.5$ & $14.0 \pm 2.5$ & $14.3 \pm 2.5$ \\
\hline SD (control II) & D W & $10.3 \pm 3.1$ & $10.4 \pm 2.5^{*}$ & $10.2 \pm 3.7$ & $10.7 \pm 2.5$ & $10.1 \pm 2.5$ \\
\hline SD (treated III) & $1000 \mathrm{mg} \mathrm{kg}^{-1}$ & $11.3 \pm 2.7$ & $12.0 \pm 2.6^{*}$ & $14.1 \pm 2.2^{* *}$ & $13.2 \pm 2.5^{*}$ & $13.1 \pm 2.8^{*}$ \\
\hline
\end{tabular}

${ }^{*} P<0.05,{ }^{* *} P<0.01$ compared to pretreatment levels.

TABLE 6: Effect of most effective dose of Trichosanthes dioica fruit aqueous extract on US and bw of severely diabetic rats (mean \pm S.D.).

\begin{tabular}{|c|c|c|c|c|c|c|}
\hline \multirow{2}{*}{ Experimental animals } & \multirow{2}{*}{ Treatment (aqueous extract) } & \multirow{2}{*}{ Pre-treatment levels } & \multicolumn{4}{|c|}{ Post-treatment levels } \\
\hline & & & 7 days & 14 days & 21 days & 28 days \\
\hline \multicolumn{7}{|c|}{ Urine Sugar } \\
\hline Normal (control I) & D W & Nil & Nil & Nil & Nil & Nil \\
\hline SD (control II) & $\mathrm{DW}$ & +++ & +++ & ++++ & ++++ & ++++ \\
\hline SD (treated III) & $1000 \mathrm{mg} \mathrm{kg}^{-1}$ & ++++ & ++++ & +++ & ++ & + \\
\hline \multicolumn{7}{|c|}{ Body weight (g) } \\
\hline Normal (control I) & D W & 200 & 200 & 210 & 210 & 210 \\
\hline SD (control II) & D W & 190 & 190 & 180 & 180 & 180 \\
\hline SD (treated III) & $1000 \mathrm{mg} \mathrm{kg}^{-1}$ & 200 & $200^{* *}$ & $210^{*}$ & $210^{*}$ & $210^{* *}$ \\
\hline
\end{tabular}

${ }^{*} P<0.05,{ }^{* *} P<0.01$ compared to pretreatment levels.

may take about 180 minutes to exhibit their hypoglycemic effect by reaching the target tissues through circulation.

The results obtained with the dose of $250 \mathrm{mg} \mathrm{kg}^{-1} \mathrm{bw}$ of the reference drug, Tolbutamide, taken as standard are comparable with the results of the most effective dose of $1000 \mathrm{mg} \mathrm{kg}^{-1}$ bw of the extract indicating thereby the possible similar mechanism of action [41, 42]. Thus, it may be the plausible mechanism by which the aqueous extract is able to decrease blood sugar level by increasing the pancreatic secretion of insulin from beta cells of islets of Langerhans [43].

Generally, it has been observed that hyperlipidemia is a complication associated with hyperglycemia [44] and the most common lipid abnormality observed is hypertriglyceridemia which increases risk factor of strokes [45]. Therefore, ideal treatment of diabetes, in addition to glycemic control, should have a favourable effect on lipid profiles [43].

Results reveal that $T$. dioica aqueous fruit extract evoked significant reductions in TC, TG, LDL, and VLDL levels of severely diabetic rats at the end of 28 days of treatment as compared to the initial. It has been found that most of the drugs that decrease TC also decrease HDL cholesterol [34] (Singh et al., 2008) but it is noteworthy to mention here that $T$. dioica had an additional advantage over the existing drugs in the way that it not only decreased the TC but also increased the cardioprotective HDL cholesterol after four weeks treatment indicating thereby that the aqueous extract of $T$. dioica fruits possesses considerable efficacy to manage elevated BGL as an aftermath of diabetes in addition to reverting the disturbed lipid profile associated with diabetes. Thus, we may say that $T$. dioica possesses modulatory effects on blood lipid abnormalities associated with diabetes. However, diabetic rats treated with the $T$. dioica aqueous extract showed an increase in body weight as compared to the diabetic control which may be attributed to its protective effect in controlling muscle wasting, that is, reversal of gluconeogenesis. Reversal of gluconeogenesis could be due to improved insulin secretion and glycemic control. Keeping in mind the herbal therapy with the T. dioica aqueous fruit extract as an alternative treatment for diabetes, toxicity was also evaluated by $\mathrm{LD}_{50}$ experiment. High value of $\mathrm{LD}_{50}$ for $T$. dioica implies its great margin of safety.

A number of lectins have been reported from T. dioica $[46,47]$. Lactines are responsible for various erythrocyte surface alterations in diabetic cases which result in impaired cell function therefore the improvement in diabetic condition on extract treatment could also be due to the presence of lectins in T. dioica extract along with other active components responsible for its antidiabetic and antilipidemic activity.

\section{Conclusions}

In conclusion, the relevance and significance of this pioneer study cannot be ignored as it reconfirms the ethnobotanical 
profile of T. dioica fruits since the aqueous extract of the plant's fruits helps in reducing the raised levels of BGL, TC, TG, LDL, VLDL, and US procured during diabetic condition. Moreover, the extract proved beneficial in enhancing the low levels of HDL, TP, and $\mathrm{Hb}$ at the end of the treatment. Significant increase in bw was an additional advantage. The extract may therefore be of considerable value to human subjects due to its high $\mathrm{LD}_{50}$, showing great margin of safety. It can thus be concluded that this plant extract promises an effective breakthrough in its potential development as a powerful oral therapeutic agent for controlling and managing diabetes mellitus.

\section{List of Abbreviations}

BGL: Blood glucose level

bw: Body weight

DW: Distilled water

FBG: Fasting blood glucose

GTT: Glucose tolerance test

h: Hours

$\mathrm{Hb}$ : Haemoglobin

HDL: High density lipoprotein

Kg: Kilogram

$\mathrm{LD}_{50}$ : Lethal dose $50 \%$

LDL: Low density lipoprotein

Mg: Milligram

PPG: Postprandial glucose

S.D.: Standard deviation

STZ: Streptozotocin

TC: Total cholesterol

TP: Total protein

TG: Triglycerides

US: Urine sugar.

\section{Acknowledgments}

The authors are thankful to Indian Council of Medical Research (ICMR), New Delhi, India and National Medicinal Plants Board (NMPB), New Delhi, India for providing financial assistance to carry out the present study.

\section{References}

[1] B. A. Khan, A. Abraham, and S. Leelamma, "Hypoglycemic action of Murraya koenigii (curry leaf) and Brassica juncea (mustard): mechanism of action," Indian Journal of Biochemistry and Biophysics, vol. 32, no. 2, pp. 106-108, 1995.

[2] S. K. Mitra, S. Gopumadhavan, T. S. Muralidhar, S. D. Anturlikar, and M. B. Sujatha, "Effect of D-400, a herbomineral preparation on lipid profile, glycated haemoglobin and glucose tolerance in streptozotocin induced diabetes in rats," Indian Journal of Experimental Biology, vol. 33, no. 10, pp. 798-800, 1995.

[3] J. D. Neaton, L. H. Kuller, D. Wentworth, and N. O. Borhani, "Total and cardiovascular mortality in relation to cigarette smoking, serum cholesterol concentration, and diastolic blood pressure among black and white males followed up for five years," American Heart Journal, vol. 108, no. 3, part 2, pp. 759$770,1984$.
[4] "WHO study group on diabetes mellitus," Technical Report Series 844, World Health Organization, Geneva, Switzerland, 1994.

[5] R. K. Gupta, A. N. Kesari, P. S. Murthy, R. Chandra, V. Tandon, and G. Watal, "Hypoglycemic and antidiabetic effect of ethanolic extract of leaves of Annona squamosa L. in experimental animals," Journal of Ethnopharmacology, vol. 99, no. 1, pp. 75$81,2005$.

[6] A. N. Kesari, R. K. Gupta, and G. Watal, "Hypoglycemic effects of Murraya koenigii on normal and alloxan-diabetic rabbits," Journal of Ethnopharmacology, vol. 97, no. 2, pp. 247-251, 2005.

[7] R. K. Gupta, A. N. Kesari, G. Watal et al., "Hypoglycaemic and antidiabetic effect of aqueous extract of leaves of Annona squamosa (L.) in experimental animal," Current Science, vol. 88, no. 8, pp. 1244-1254, 2005.

[8] D. Jaiswal, P. Kumar Rai, A. Kumar, S. Mehta, and G. Watal, "Effect of Moringa oleifera Lam. leaves aqueous extract therapy on hyperglycemic rats," Journal of Ethnopharmacology, vol. 123, no. 3, pp. 392-396, 2009.

[9] P. K. Rai, S. Mehta, and G. Watal, "Hypolipidaemic \& hepatoprotective effects of Psidium guajava raw fruit peel in experimental diabetes," Indian Journal of Medical Research, vol. 131, no. 6, pp. 820-824, 2010.

[10] S. Shukla, P. K. Rai, S. Chatterji, N. K. Rai, A. K. Rai, and G. Watal, "LIBS based screening of glycemic elements of Ficus religiosa," Food Biophysics, vol. 7, no. 1, pp. 43-49, 2012.

[11] H. M. Chakravarthy, "Fascicles of flora of India-11 Cucurbitacae," Botanical Survey of India, p. 136, 1982.

[12] G. Sharma and M. C. Pant, "Effect of feeding Trichosanthes dioica (parval) whole fruits on blood glucose, serum triglycerides, phospholipid, cholesterol and high density lipoproteincholesterol levels in the normal albino rabbits," Current Science, vol. 57, no. 19, pp. 1085-1087, 1988.

[13] P. K. Rai, D. Jaiswal, S. Diwakar, and G. Watal, "Antihyperglycemic profile of Trichosanthes dioica seeds in experimental models," Pharmaceutical Biology, vol. 46, no. 5, pp. 360-365, 2008.

[14] P. K. Rai, D. Jaiswal, R. K. Singh, R. K. Gupta, and G. Watal, "Glycemic properties of Trichosanthes dioica leaves," Pharmaceutical Biology, vol. 46, no. 12, pp. 894-899, 2008.

[15] M. A. A. Rahman and S.-S. Moon, "Isoetin 5 '-methyl ether, a cytotoxic flavone from Trichosanthes kirilowii," Bulletin of the Korean Chemical Society, vol. 28, no. 8, pp. 1261-1264, 2007.

[16] P. Knekt, J. Kumpulainen, R. Järvinen et al., "Flavonoid intake and risk of chronic diseases," American Journal of Clinical Nutrition, vol. 76, no. 3, pp. 560-568, 2002.

[17] B.-S. Ko, S. B. Choi, S. K. Park, J. S. Jang, Y. E. Kim, and S. Park, "Insulin sensitizing and insulinotropic action of berberine from Cortidis rhizoma," Biological and Pharmaceutical Bulletin, vol. 28, no. 8, pp. 1431-1437, 2005.

[18] T. Bobkiewicz-Kozłowska, M. Dworacka, S. Kuczyński et al., "Hypoglycaemic effect of quinolizidine alkaloids-lupanine and 2-thionosparteine on non-diabetic and streptozotocininduced diabetic rats," European Journal of Pharmacology, vol. 565, no. 1-3, pp. 240-244, 2007.

[19] S. H. Kim, E.-J. Shin, E.-D. Kim, T. Bayaraa, S. C. Frost, and C.K. Hyun, "Berberine activates GLUT1-mediated glucose uptake in 3T3-L1 adipocytes," Biological and Pharmaceutical Bulletin, vol. 30, no. 11, pp. 2120-2125, 2007.

[20] H. A. Jung, N. Y. Yoon, H. J. Bae, B.-S. Min, and J. S. Choi, "Inhibitory activities of the alkaloids from Coptidis Rhizoma 
against aldose reductase," Archives of Pharmacal Research, vol. 31, no. 11, pp. 1405-1412, 2008.

[21] W. Zhang, Y.-C. Xu, F.-J. Guo, Y. Meng, and M.-L. Li, "Antidiabetic effects of cinnamaldehyde and berberine and their impacts on retinol-binding protein 4 expression in rats with type 2 diabetes mellitus," Chinese Medical Journal, vol. 121, no. 21, pp. 2124-2128, 2008.

[22] B. Sharma, R. Salunke, C. Balomajumder, S. Daniel, and P. Roy, "Anti-diabetic potential of alkaloid rich fraction from Capparis decidua on diabetic mice," Journal of Ethnopharmacology, vol. 127, no. 2, pp. 457-462, 2010.

[23] T. Kanchanapoom, R. Kasai, and K. Yamasaki, "Cucurbitane, hexanorcucurbitane and octanorcucurbitane glycosides from fruits of Trichosanthes tricuspidata," Phytochemistry, vol. 59, no. 2, pp. 215-228, 2002.

[24] S. Cherian, R. V. Kumar, K. T. Augusti, and J. R. Kidwai, "Antidiabetic effect of a glycoside of pelargonidin isolated from the bark of Ficus bengalensis Linn," Indian Journal of Biochemistry and Biophysics, vol. 29, no. 4, pp. 380-382, 1992.

[25] T. Akihisa, Y. Kimura, Y. Kasahara, K. Kumaki, S. Thakur, and T. Tamura, "7-oxodihydrokarounidiol-3-benzoate and other triterpenes from the seeds of cucurbitaceae," Phytochemistry, vol. 46, no. 7, pp. 1261-1266, 1997.

[26] R. M. Perez G. and R. Vargas S., "Triterpenes from Agarista mexicana as potential antidiabetic agents," Phytotherapy Research, vol. 16, no. 1, pp. 55-58, 2002.

[27] B. C. Hatapakki, H. M. Suresh, V. Bhoomannavar, and S. I. Shivkumar, "Effect of Cassia auriculata Linn flowers against alloxan-induced diabetes in rats," Journal of Natural Remedies, vol. 5, no. 2, pp. 132-136, 2005.

[28] G. Sharma, A. Sarkar, S. B. Pachori, and M. C. Pant, "Biochemical evaluation of raw Trichosanthes dioica whole fruit and pulp in normal and mild diabetic human volunteers in relation to lipid profile," Indian Drug, vol. 27, no. 1, pp. 24-28, 1989.

[29] M. Elson and M. D. Haas, "Role of potassium in maintaining health," 2007, http://hkpp.org/patients/potassium-health.

[30] G. Y. Yeh, D. M. Eisenberg, T. J. Kaptchuk, and R. S. Phillips, "Systematic review of herbs and dietary supplements for glycemic control in diabetes," Diabetes Care, vol. 26, no. 4, pp. 1277-1294, 2003.

[31] R. Lopez-Ridaura, W. C. Willett, E. B. Rimm et al., "Magnesium intake and risk of type 2 diabetes in men and women," Diabetes Care, vol. 27, no. 1, pp. 134-140, 2004.

[32] A. Kar, B. K. Choudhary, and N. G. Bandyopadhyay, "Preliminary studies on the inorganic constituents of some indigenous hypoglycaemic herbs on oral glucose tolerance test," Journal of Ethnopharmacology, vol. 64, no. 2, pp. 179-184, 1999.

[33] Brahamvarchas, "Ayurveda ka pran: vana aushidhi vigyan," pp. 450-451, 3rd edition, 2003.

[34] S. K. Singh, P. K. Rai, D. Jaiswal, and G. Watal, "Evidence-based critical evaluation of glycemic potential of Cynodon dactylon," Evidence-Based Complementary and Alternative Medicine, vol. 5, no. 4, pp. 415-420, 2008.

[35] D. Barham and P. Trinder, "An improved colour reagent for the determination of blood glucose by the oxidase system," The Analyst, vol. 97, no. 1151, pp. 142-145, 1972.

[36] C. C. Allain, L. S. Poon, C. S. G. Chan, W. Richmond, and P. C. Fu, "Enzymatic determination of total serum cholesterol," Clinical Chemistry, vol. 20, no. 4, pp. 470-475, 1974.

[37] G. Bucolo and H. David, "Quantitative determination of serum triglycerides by the use of enzymes," Clinical Chemistry, vol. 19, no. 5, pp. 476-482, 1973.
[38] W. T. Friedewald, R. I. Levy, and D. S. Fredrickson, "Estimation of the concentration of low-density lipoprotein cholesterol in plasma, without use of the preparative ultracentrifuge," Clinical Chemistry, vol. 18, no. 6, pp. 499-502, 1972.

[39] R. D. Strickland, M. L. Freeman, and F. T. Gurule, "Copper binding by proteins in alkaline solution," Analytical Chemistry, vol. 33, no. 4, pp. 545-552, 1961.

[40] M. Nonfon, F. Lieb, H. Moeschler, and D. Wendisch, "Four annonins from Annona squamosa," Phytochemistry, vol. 29, no. 6, pp. 1951-1954, 1990.

[41] M. D. Ivorra, M. Paya, and A. Villar, "A review of natural products and plants as potential antidiabetic drugs," Journal of Ethnopharmacology, vol. 27, no. 3, pp. 243-275, 1989.

[42] S. B. Sharma, A. Nasir, K. M. Prabhu, and P. S. Murthy, "Antihyperglycemic effect of the fruit-pulp of Eugenia jambolana in experimental diabetes mellitus," Journal of Ethnopharmacology, vol. 104, no. 3, pp. 367-373, 2006.

[43] I.-M. Chung, E.-H. Kim, M.-A. Yeo, S.-J. Kim, M.-C. Seo, and H.-I. Moon, "Antidiabetic effects of three Korean sorghum phenolic extracts in normal and streptozotocin-induced diabetic rats," Food Research International, vol. 44, no. 1, pp. 127-132, 2011.

[44] S. R. Sharma, S. K. Dwivedi, and D. Swarup, "Hypoglycaemic and hypolipidemic effects of Cinnamomum tamala Nees leaves," Indian Journal of Experimental Biology, vol. 34, no. 4, pp. 372374, 1996.

[45] A. Sachdewa and L. D. Khemani, "Effect of Hibiscus rosa sinensis Linn. ethanol flower extract on blood glucose and lipid profile in streptozotocin induced diabetes in rats," Journal of Ethnopharmacology, vol. 89, no. 1, pp. 61-66, 2003.

[46] P. D. Dharkar, P. Anuradha, S. M. Gaikwad, and C. G. Suresh, "Crystallization and preliminary characterization of a highly thermostable lectin from Trichosanthes dioica and comparison with other Trichosanthes lectins," Acta Crystallographica F, vol. 62, no. 3, pp. 205-209, 2006.

[47] N. A. M. Sultan, R. Kenoth, and M. J. Swamy, "Purification, physicochemical characterization, saccharide specificity, and chemical modification of a Gal/GalNAc specific lectin from the seeds of Trichosanthes dioica," Archives of Biochemistry and Biophysics, vol. 432, no. 2, pp. 212-221, 2004. 

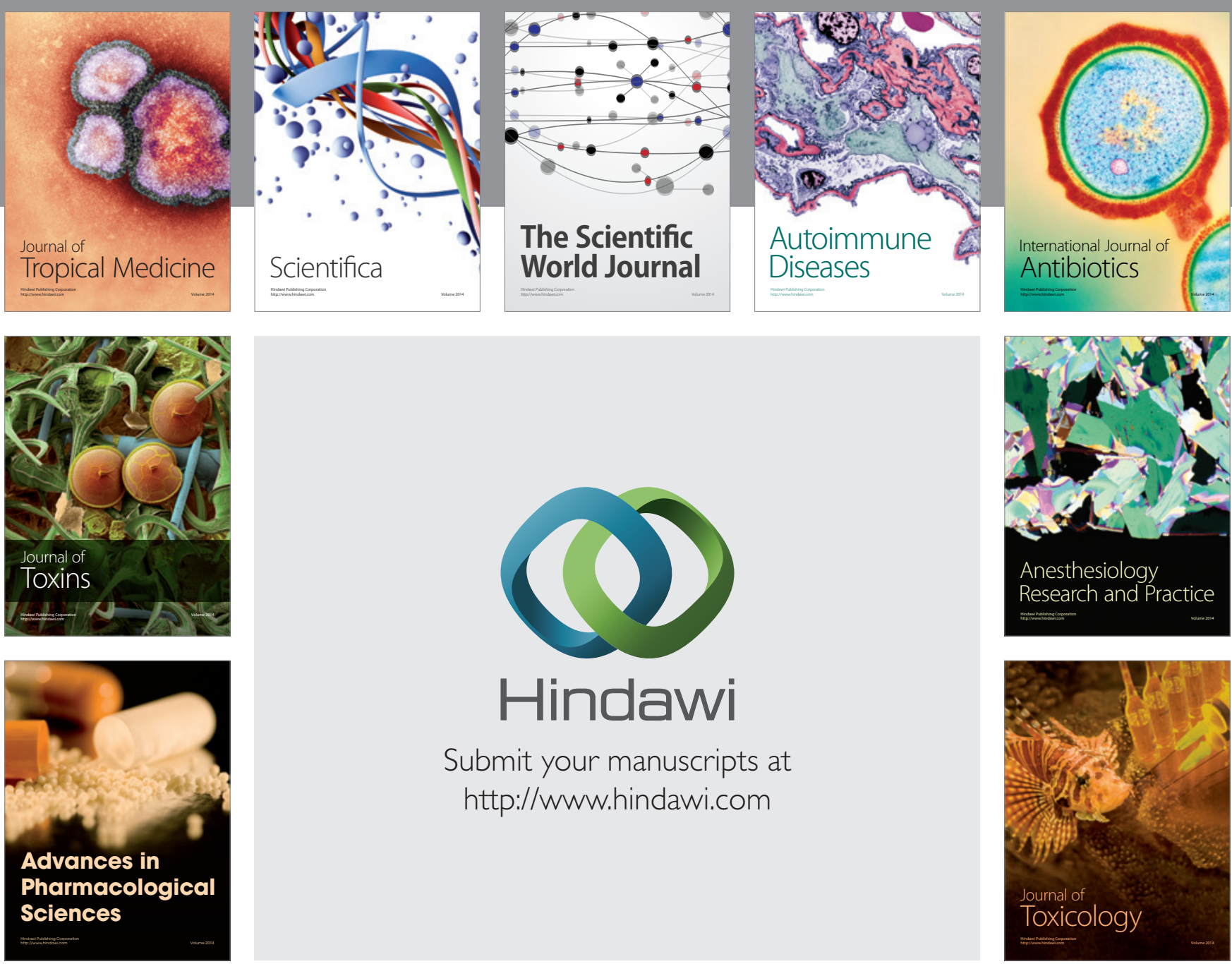

\section{Hindawi}

Submit your manuscripts at

http://www.hindawi.com
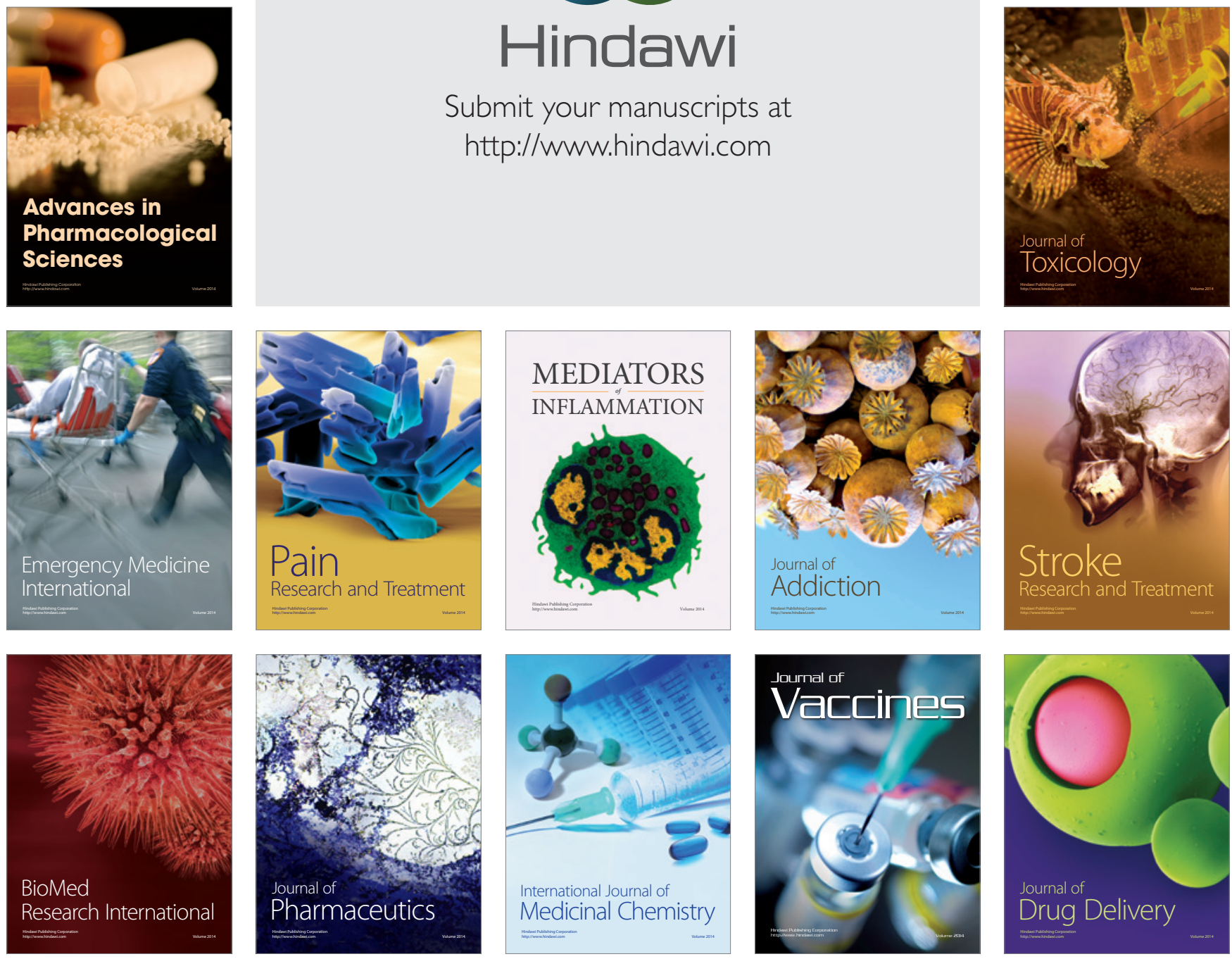